\title{
Rabbit Galig Discovery and its Prokaryotic Recombinant Protein Expression
}

\author{
Enhao Fang ${ }^{2}$, Shanshan Zhang ${ }^{3}$, XianyuYang ${ }^{*}$, Xin Gao ${ }^{1}$ \\ ${ }^{1}$ College of Animal Science and Technology, Zhejiang Agricultural and Forestry University, 666 Wusu Street, \\ Hangzhou, Zhejiang, 311300, China \\ ${ }^{2}$ Jixian Honors College, Zhejiang Agricultural and Forestry University, 666 Wusu Street, Hangzhou, Zhejiang \\ 311300, China \\ ${ }^{3}$ School of Forestry and Biotechnology, Zhejiang Agricultural and Forestry University, 666 Wusu Street \\ Hangzhou, Zhejiang 311300, China
}

*Corresponding Author: XianyuYang, College of Animal Science and Technology, Zhejiang Agricultural and Forestry University, 666 Wusu Street, Hangzhou, Zhejiang 311300, China, Email: yangxy78@zafu.edu.cn

\begin{abstract}
In the process of cloning and analyzing rabbit (Oryctolagus cuniculus) galectin-3 (gal-3) cDNA, authors found that its open reading frame (ORF) is 729 bp encoding Gal-3 consisting of 242 amino acid residues, which is consistent with previous report. Meanwhile, two galig ORFs embedded in gal-3 were found, whose encoding polypeptides are completely different from that of Gal-3 but show 58\% and 57\% homology with human Cytogaligin and Mitogaligin, respectively. So far, the function of apoptosis induction has been reported for human Cytogaligin and Mitogaligin by transfection experiments. In consideration of the importance of further investigation on Cytogaligin and Mitogaligin, and the lack of direct detection of their apoptotic activity with protein samples, prokaryotic expression constructs of rabbit pET-28b-cytogaligin and pET-28b-mitogaligin as well as pET-28b-gal-3 were made in current investigation, however only recombinant Gal-3 and Cytogaligin of rabbit were well expressed.
\end{abstract}

Keywords: Cytogaligin; galectin-3; galig; Oryctolagus cuniculus; Prokaryotic expression

\section{INTRODUCTION}

Galectin-3 (Gal-3) as a multi-functional protein, is capable of specifically recognizing and binding to $\beta$-galactosides, which is widely expressed in normal cells (such as epithelial cells and immune cells) and tumor cells, and involved in a variety of life processes including cell growth, differentiation, adhesion, angiogenesis, tumor progression and metastasis ${ }^{[1-9]}$. galig was initially reported in human as galectin-3 internal gene, whose two open reading frames (ORF) are embedded in gal-3 ORF encoding two polypeptides, Cytogaligin and Mitogaligin ${ }^{[10]}$. Their amino acid sequences are completely different from that of Gal-3, and both of them have been evidenced to have the ability to induce cell apoptosis by transfection experiments ${ }^{[10-13]}$. In current study, the authors found that a similar case exists in rabbit (Oryctolagus cuniculus) in the process of analyzing gal-3 ORF. In consideration of the lack of direct evidence to detect their function of apoptosis induction, three prokaryotic expression constructs of rabbit have been made including pET-28b-gal-3, pET-28b-cytogaligin and pET-28bmitogaligin. As the results, the first two recombinant proteins (Gal-3 and Cytogaligin) were induced successfully, which will become the basis for the further studies of Cytogaligin functions including detection of its apoptotic induction activity and preparation of its antiserum for its quantitative expression analysis in organisms.

\section{MATERIALS AND METHODS}

\subsection{Experimental Animals}

Rabbits (Oryctolagus cuniculus) were purchased from the Experimental Animal Center, Zhejiang, China. According to the Guide for Care and Use of Laboratory Animals published by the US National Institutes of Health (NIH Publication No. 85-23, revised 1996), the rabbits were killed by 
intravenous injection of air before operation. Then their livers were taken out and chopped into liquid nitrogen quickly, and then kept in $-70^{\circ} \mathrm{C}$ refrigerator.

\subsection{Main Experimental Materials and Reagents}

Escherichia coli (E. coli) competent cells, Top10 and BL21(DE3) and cDNA first strand synthesis kit (Quantscript RT kit) were purchased from Tiangen Technology Limited Company (Beijing, China); rTaq DNA polymerase chain reaction (PCR) kit and Prime STAR Max PCR kit, DNA restriction enzymes (XbaI, HindIII, XhoI) and Talon xTractor Buffer were from TAKARA (Dalian, China); DNA ladder, protein marker, T4 ligase, PVDF membrane, anti-mouse His-tag antibody, horseradish peroxidase (HRP)-conjugated goat anti-mouse antibody and hypersensitivity ECL chemiluminescence kit from Biyuntian Biotechnology Research Institute (Nantong, China); seamless cloning kit (GBclonart mix) from GBI Company, pcDNA3.1 (+) from Invitrogen, DNA gel extraction kit and plasmid extraction kit from Axygen, prokaryotic expression vector pET-28b (+) from Novagen, and RNA extraction kit from Bocai Biotechnology Company (Shanghai, China). Primer synthesis and DNA sequencing were commissioned to Sangni Biotechnology Company (Shanghai, China).

\subsection{Methods}

Most procedures of gene cloning and subcloning, and recombinant protein expression described in the following sections are referred and followed $\mathrm{CaO}^{[14]}$.

Primer design Based on the rabbit gal-3 cDNA sequence registered in GenBank (NP_001075807) and seamless cloning kit instructions, a set of primers (P1 and P2) were designed to clone rabbit gal-3 ORF (Table 1), in which the uppercase part was copied from part of the rabbit gal-3 ORF, while the lowercase part from pcDNA3.1 being used as a cloning vector in current study. For the preparation of prokaryotic expression constructs, pET-28b (+) was used as vectors, and Xba I and Xho I as cloning sites. Meanwhile three sets of primers, P3 and P4, P5 and P6, P7 and P8 were designed for subcloning of rabbit Gal-3, Cytogalig and Mitogalig ORF, respectively (Table 1).

Table1. Primer sequences used in current study

\begin{tabular}{|l|l|}
\hline Primer & \multicolumn{1}{c|}{ Sequence $\left(\mathbf{5}^{\prime} \mathbf{-} \mathbf{3}^{\prime}\right.$ ) } \\
\hline P1 & tagcgtttaaacttaagcttgcATGGCGGATGGTTTTCGC \\
\hline P2 & atcgtccttatagtctctagaTTATATCATAGCATGTGAAGCA \\
\hline P3 & AAGAAGGAGATATACCATGGCGGATGGTTTTTCGC \\
\hline P4 & TGGTGGTGGTGGTGCTCGAGTATCATAGCATGTGAAGCAC \\
\hline P5 & AAGAAGGAGATATACCATGGTTTTCGCTCAACGA \\
\hline P6 & TGGTGGTGGTGGTGCTCGAGGCATGCGGGGCATGAC \\
\hline P7 & AAGAAGGAGATATACCATGGCCTGGCCCATGGG \\
\hline P8 & TGGTGGTGGTGGTGCTCGAGTAAGGCACAGGCAGTGG \\
\hline
\end{tabular}

RNA extraction and first-strand cDNA synthesis According to the instructions for RNA extraction and the first strand cDNA synthesis, the total RNA of rabbit liver was purified, whose integrity and purity were detected by both spectrophotometer and agarose gel electrophoresis. Then its first strand cDNA was synthesized.

Rabbit gal-3 ORF cloning Gal-3 ORF amplification: According to Prime STAR Max kit instructions, PCR was performed using rabbit liver first strand cDNA as a template, P1 and P2 as primers. Reaction system: $2 \times$ Prime STAR Max premix $10 \mu \mathrm{L}$, the first strand cDNA $1 \mu \mathrm{L}, \mathrm{P} 1$ and P2 of $1 \mu \mathrm{L}$ each $(2 \mathrm{pmol} / \mu \mathrm{L})$, added sterilized water to $20 \mu \mathrm{L}$. Cycling parameters: $98^{\circ} \mathrm{C} 2 \mathrm{~min} ;\left(98^{\circ} \mathrm{C} 10 \mathrm{~s}, 50^{\circ} \mathrm{C}\right.$ $\left.15 \mathrm{~s}, 72^{\circ} \mathrm{C} 10 \mathrm{~s}\right), 5$ cycles; $\left(98^{\circ} \mathrm{C} 10 \mathrm{~s}, 55^{\circ} \mathrm{C} 5 \mathrm{~s}, 72^{\circ} \mathrm{C} 10 \mathrm{~s}\right), 30$ cycles. PCR products were detected by agarose gel electrophoresis. Then according to the instructions of seamless cloning kit, PCR products were ligated into pcDNA $3.1(+)$ and transformed into Top10 competent cells. Ligation system: PCR product $1 \mu \mathrm{L}$ (about $25 \mathrm{ng}$ ), pcDNA3.1 (+) $0.5 \mu \mathrm{L}$ (digested with HindIII and Xba I, $50 \mathrm{ng} / \mu \mathrm{L}$ ), GBclonart mix $7.5 \mu \mathrm{L}$, added sterilized water to $10 \mu \mathrm{L}$. The mixture was incubated at $50^{\circ} \mathrm{C}$ for 30 min, and then put on ice immediately. Transformation: $2 \mu \mathrm{L}$ of ligation products was mixed with 50 $\mu \mathrm{L}$ E. coli Top 10 competent cells, which was kept on ice for $30 \mathrm{~min}$ and followed by $90 \mathrm{~s}$ heattreatment at $42^{\circ} \mathrm{C}$. The heat-treated sample was replaced on ice for $2 \mathrm{~min}$, in which $400 \mu \mathrm{L} 37^{\circ} \mathrm{C}$ prewarmed LB medium without any antibiotics was added, and incubated in $37^{\circ} \mathrm{C}$ shaker for $45 \mathrm{~min}$. Finally, the transformation sample was spread on LB plates containing ampicilin $(100 \mu \mathrm{g} / \mathrm{mL})$ and kept for $15 \mathrm{~h}$ in a $37^{\circ} \mathrm{C}$ incubator. Then single colonies were suspended in $10 \mu \mathrm{L}$ LB medium being 
used as templates for colony PCR [colony suspension $0.5 \mu \mathrm{L}, 1 \mu \mathrm{L}$ of $10 \times r$ Taq PCR buffer, $1 \mu \mathrm{L}$ of dNTPs $(10 \mathrm{~mol} / \mu \mathrm{L}), 1 \mu \mathrm{L}$ of T7, the upstream primer of pcDNA3.1(+), and $1 \mu \mathrm{L}$ of gene specific primer P2 $(2 \mathrm{pmol} / \mu \mathrm{L}), r T a q 0.2 \mu \mathrm{L}(5 \mathrm{U} / \mu \mathrm{L})$, add sterilized water to $10 \mu \mathrm{L}]$. PCR cycles: $94^{\circ} \mathrm{C} 3$ $\min ;\left(94^{\circ} \mathrm{C} 30 \mathrm{~s}, 52^{\circ} \mathrm{C} 30 \mathrm{~s}, 72{ }^{\circ} \mathrm{C} 1 \mathrm{~min}\right), 30$ cycles. PCR product was detected by $1 \%$ of agarose gel electrophoresis. The positive colonies were tentatively determined by the appearance of a reasonable PCR product, whose remaining bacteria suspension was inoculated in $2 \mathrm{~mL} \mathrm{LB}$ medium (ampicilin: $100 \mu \mathrm{g} / \mathrm{mL}$ ) and cultured at $37^{\circ} \mathrm{C}$ shaker for $15 \mathrm{~h}$. Then the plasmid was extracted from the culture and digested with $\mathrm{Xba}$ I and HindIII followed by agarose gel electrophoresis. Finally, the positive recombinant plasmid was designated as pcDNA3.1-gal-3 and commissioned for sequencing using vector upstream primer, T7.

Sequence analysis DNA star / EditSeq was used to find ORF, deducing amino acid sequence of the encoded protein and analyzing their physical and chemical properties; NCBI blast function was used to download the homologous amino acid sequences of other species from GenBank; ClustalX 2.0 was used for homology analysis.

Construction of prokaryotic expression recombinant plasmid ${ }^{[15]}$ PCR was performed using rabbit recombinant plasmid pcDNA3.1-gal-3 as template, and three sets of primers (P3 and P4, P5 and P6, P7 and P8). PCR products were subjected to $1 \%$ agarose gel electrophoresis and gel extraction, which were digested with $X b a$ I and Xho I, and ligated into pET-28b ( $X b a$ I and Xho I digested) using T4 ligase system. The following experiments including transformation, positive colony screening, recombinant plasmid extraction and sequencing, all followed as described above. Three constructs were designated as pET-28b-gal-3, pET-28b-cytogaligin and pET-28b-mitogaligin, respectively.

Induction of recombinant protein expression and western blotting analysis ${ }^{[14]}$ According to pET-28b instructions, the IPTG induction and Western blotting analysis of the recombinant proteins were performed as following. Firstly, pET-28b-gal-3, pET-28b-cytogaligin and pET-28b-mitogaligin were transformed into E. coli BL21 (DE3), respectively. The pre-culture was made one day before the recombinant protein induction by inoculating a single colony in LB medium containing antibiotics of kanamycin (final concentration: $50 \mu \mathrm{g} / \mathrm{mL}$ ). For recombinant protein induction, $1 \mathrm{~mL}$ pre-culture was inoculated into $100 \mathrm{~mL} \mathrm{LB}$ medium (kanamycin $50 \mu \mathrm{g} / \mathrm{mL}$ ), and when $\mathrm{OD}_{600}$ reached 0.7 , IPTG solution was added in (final concentration of $1 \mathrm{mmol} / \mathrm{L}$ ). To determine the optimal induction time, 0.5 $\mathrm{mL}$ culture was sampled every one hour till $4 \mathrm{~h}$ after IPTG addition. By centrifugation, the bacteria were collected and then dissolved in $50 \mu \mathrm{L} 1 \times$ protein loading buffer, and $5 \mu \mathrm{L}$ was loaded on $15 \%$ SDS-PAGE for detection of recombinant protein expression.

Western blotting analysis The gel, the same size cuts of PVDF membrane and filter paper as gel size were immersed in transfer buffer after SDS-PAGE. Then a sandwich was assembled in the order of filter paper, gel, PVDF membrane and filter paper from anode to cathode, which was applied $65 \mathrm{~V}$ for $3 \mathrm{~h}$. After transfer, PVDF membrane was treated in blocking solution for $2 \mathrm{~h}, 1000 \times$ diluted mouse anti-His-tag antibody overnight at $4^{\circ} \mathrm{C}$ and $1000 \times$ diluted HRP-conjugated goat anti-mouse secondary antibody at room temperature for $2 \mathrm{~h}$. Then the PVDF membrane was treated with ECL chemiluminescence kit by covering it with the mixture of A and B solutions for 5 min. Then PVDF membrane was wrapped and used to exposure the film in the darkroom. Finally, the film was developed, air-dried and scanned for figure preparation.

Solubility analysis of recombinant proteins According to the instructions, the bacteria expressed the recombinant protein was dissolved in Talon xTractor. After centrifugation, the supernatant and the pellete were detected on SDS-PAGE. The soluble proteins were distributed in the supernatant, while insoluble proteins in the pellete.

\section{RESULTS}

\subsection{Rabbit Gal-3 ORF Cloning and Galig ORF Discovery}

Using rabbit liver first strand cDNA as template, and P1 and P2 as primers, a specific PCR product closed to the expected 729 bp of rabbit gal-3 ORF was obtained (Fig. 1). Sequencing result indicated that the PCR product was completely the same as the sequence registered in GenBank (accession No: NP_001075807) (Fig. 2). Meanwhile, sequence analysis indicated two ORFs embedded in rabbit gal3 ORF encoding two polypeptides different from Gal-3 (Fig. 2). Their deduced amino acid sequences showed 58\% and 57\% homology with human Cytogaligin (AAG44701.1) and Mitogaligin 
(AAG44702.1), respectively (Fig. 3 and 4). Here, these two ORFs were desingnated as rabbit galig encoding rabbit Cytogaligin and Mitogaligin.

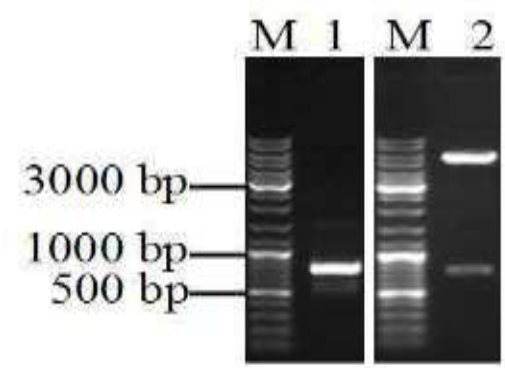

Figure 1 The cloning of Oryctolagus cuniculus gal-3 ORF

M: DNA ladder; 1: PCR products; 2: Hind III and Xba I digestion of pcDNA3.1-gal-3.

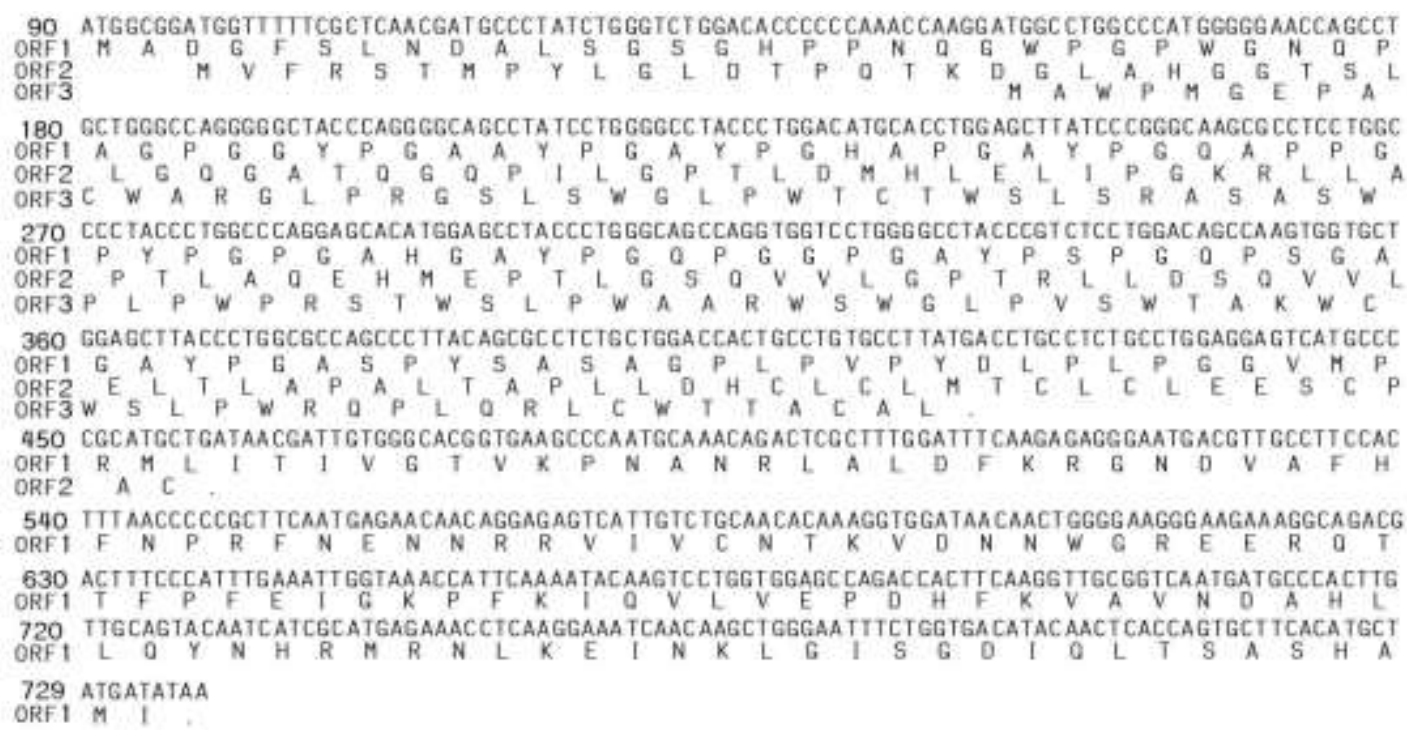

Figure 2 Two galig ORFs embedded in gal-3 ORF and their deduced amino acid sequences of Oryctolagus cuniculus

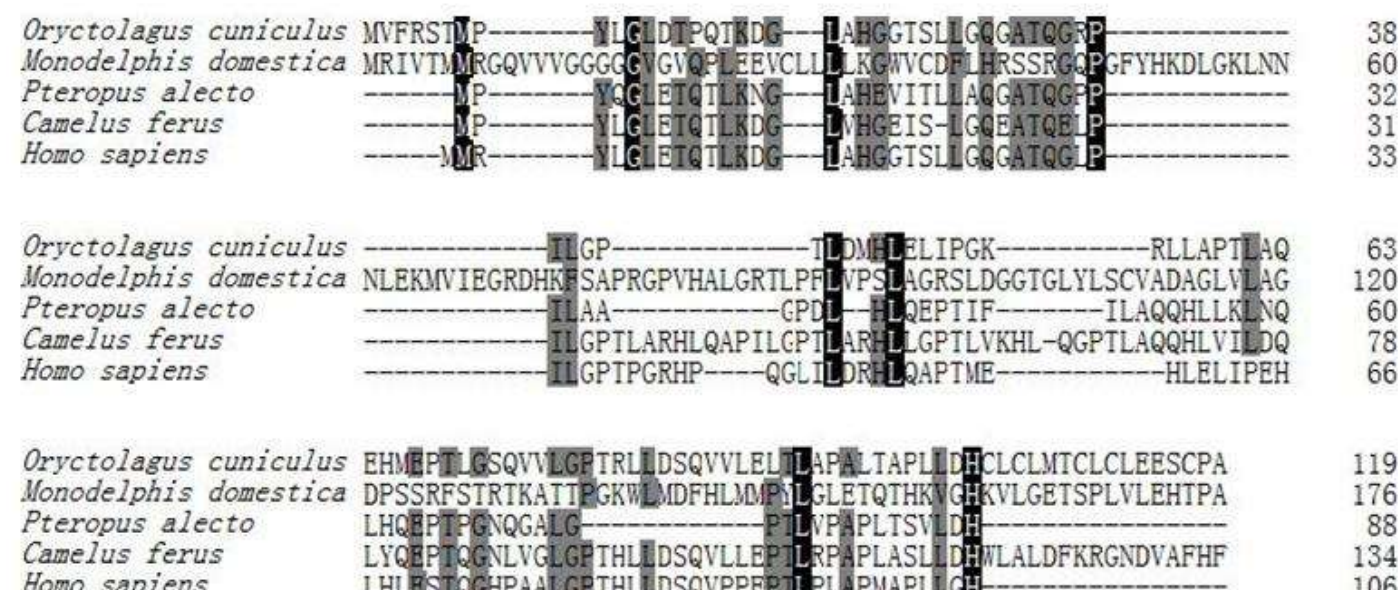

Figure 3 Homologous analysis of Cytogaligin between Oryctolagus cuniculus and other animals

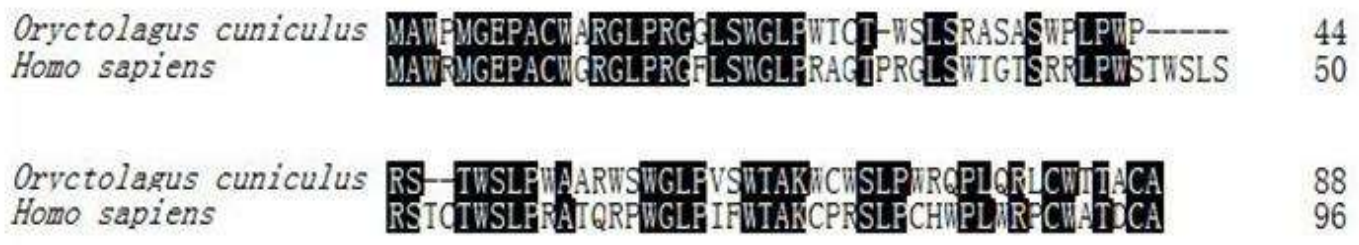

Figure 4 Homologous analysis of Mitogaligin between Oryctolagus cuniculus and Homo sapiens 


\subsection{Subcloning of Rabbit Gal-3, Cytogaligin and Mitogaligin}

Using rabbit recombinant plasmid pcDNA3.1-gal-3 as template, three ORFs encoding rabbit Gal-3, Cytogaligin and Mitogaligin were amplified (Fig. 5), whose correct insertion into pET28b (pET-28bgal-3, pET-28b-cytogalig, pET-28b-mitogalig) was confirmed by sequencing analysis. The predicted molecular weight of recombinant Gal-3, Cytogaligin and Mytogaligin are 26.595, 13.765 and 11.419 $\mathrm{kD}$, respectively.

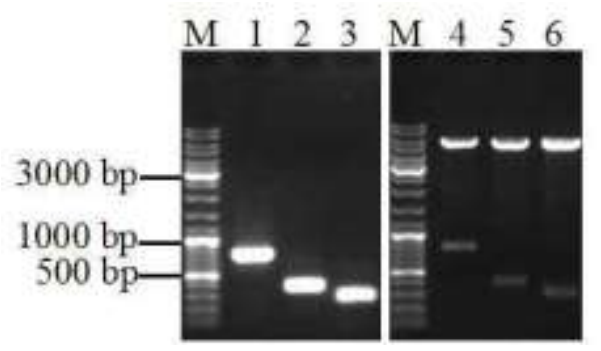

Figure 5 The subcloning of Oryctolagus cuniculus gal-3 and galig

M: DNA ladder; 1-3: PCR products of gal-3 ORF, cytogalig ORF and mitogalig ORF, respectively; 46: Xba I and Xho I digestion of pET-28b-gal-3, pET-28b-cytogalig and pET-28b-mitogalig.

\subsection{Induction and Expression Analysis of Recombinant Proteins}

SDS-PAGE analysis indicated the expressions of rabbit recombinant Gal-3 and Cytogaligin (Fig. 6). In case of rabbit Gal-3, a prominent protein band appeared in IPTG-induced samples at the location of a little bit higher than the protein marker of $25.0 \mathrm{kD}$, which is consistent with predicted molecular weight of $26.595 \mathrm{kD}$ (Fig. 6, compare lane 1 and 2). In case of Cytogaligin, an overexpressed protein was observed at the position of a little bit lower than the protein marker of $14.4 \mathrm{kD}$ consistent with its predicted molecular weight $13.765 \mathrm{kD}$ (Fig. 6, compare lane 3 and 4). Western blotting analysis confirmed the results of SDS-PAGE analysis (Fig. 6, compare lane 5 and 6, 7 and 8). However, no induction of recombinant Mitogaligin was detected (data not shown). Solubility analysis showed that recombinant Gal-3 was soluble, Cytogaligin was insoluble (Fig. 7).

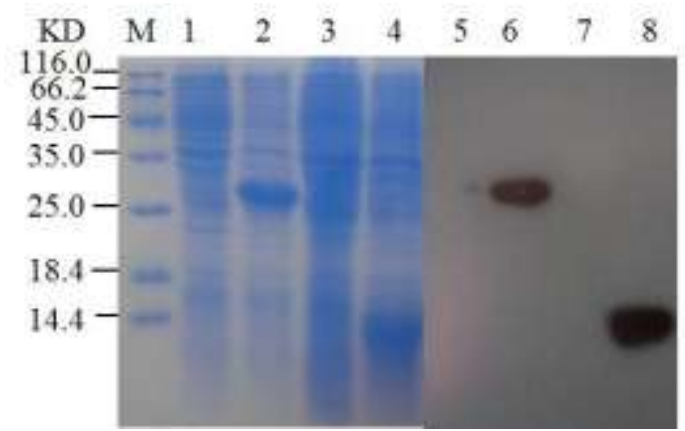

Figure 6 Gal-3 and Cytogligin recombinant protein anlysis of Oryctolagus cuniculus.

kD: Kilodalton; M: Protein marker; 1-4: Coomassie brilliant blue staining; 5-8: Western blotting; 1, 5 : Gal-3 samples without IPTG induction; 3, 7: Cytogligin samples without IPTG induction; 2, 6: Gal3 samples after $4 \mathrm{~h}$ IPTG induction; 4, 8: Cytogligin samples after $2 \mathrm{~h}$ IPTG induction.

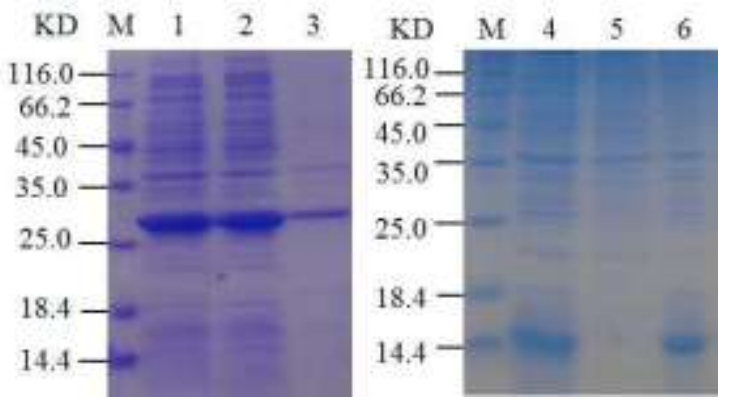

Figure 7 Solubility analysis of Gal-3 and Cytogaligin recombinant proteins of Oryctolagus cuniculus by SDSPAGE.

kD: Kilodalton; M: Protein marker; 1-3: Gal-3 recombinant protein; 4-6: Cytogaligin recombinant protein. 1, 4: Whole bacteria; 2, 5: Supernatant; 3, 6: Pelletes. 


\section{DISCUSSION}

In current study, two galig ORFs embedded in rabbit gal-3 ORF were reported, whose encoding polypeptides have completely different amino acid sequences from that of Gal-3 itself (Fig. 2). However, they showed homology with human Cytogaligin and Mitogaligin (Fig. 3 and 4), both of which have been reported to induce cell apoptosis by transfection experiments ${ }^{[10]}$. Mitogaligin is located in the mitochondria, and can induce the release of cytochrome c, ultimately cell death ${ }^{[11,12]}$. Cytogaligin mainly produced in the cytoplasm and nucleus, can also induce cell apoptosis ${ }^{[1]}$. Therefore, further studies on cytogaligin and mitogaligin will prospect new anti-tumor drug development. Successful prokaryotic expression of rabbit recombinant Cytogaligin as well as Gal-3 (Fig. 6 and 7) in current study makes it possible to obtain large amount of recombinant proteins, which could be used to detect their pharmaceutical effects directly, meanwhile could provide antigen for their antiserum preparation, which will be very important for their quantitative expression analysis in organisms.

\section{ACKNOWLEDGEMENTS}

This work was partially supported by the grant from National Natural Science Foundation of China (No. 31772409, 31372149).

\section{REFERENCES}

[1] Krzeslak A, Lipinska A. Galectin-3 as a multifunctional protein. Cell Mol Biol Lett, 2004, 9(2): 305-328.

[2] Takenaka Y, Fukumori T, Raz A. Galectin-3 and metastasis. Glycoconj J, 2004, 19(7-9): 543-549.

[3] Nakahara S, Oka N, Raz A. On the role of galectin-3 in cancer apoptosis. Apoptosis, 2005, 10(2): 267-275.

[4] Barondes SH, Cooper DN, Gitt MA, Leffler H. Galectins. Structure and function of a large family of animal lectins. J Biol Chem, 1994, 269: 20807-20810.

[5] Liu FT, Patterson RJ, Wang JL.Intracellular functions of galectins. Biochim Biophys Acta, 2002, 1572: 263-273.

[6] Matarrese P, Fusco O, Tinari N, Natoli C, Liu FT, Semeraro ML, Malorni W, Iacobelli S. Galectin-3 overexpression protects from apoptosis by improving cell adhesion properties. Int J Cancer, 2000, 85: 545-554.

[7] Yang RY, Hsu DK, Liu FT. Expression of galectin-3 modulates T-cell growth and apoptosis. Proc Natl Acad Sci U S A, 1996, 93: 6737-6742.

[8] Yoshii T, Fukumori T, HonjoY, Inohara H, Kim HR, Raz A. Galectin-3 phosphorylation is required for its anti-apoptotic function and cell cycle arrest. J Biol Chem, 2002, 277: 6852-6857.

[9] Fukumori T, Takenaka Y, Yoshii T, Kim HR, Hogan V, Inohara H, Kagawa S, Raz A. CD29 and CD7 mediate galectin-3-induced type II T-cell apoptosis. Cancer Res, 2003, 63: 8302-8311.

[10] Gutaut M, Charpentier S, Normand T, Dubois M, Raimond J, Legrand A. Identification of an internal gene to the human Galectin-3 gene with two different overlapping reading frames that do not encode Galectin-3. J Biol Chem, 2001, 276: 2652-2657.

[11] Duneau M, Guttaut M, Gonzalez P, Charpentier S, Normand T, Dubois M, Raimond J, Legrand A. Galig, a novel cell death gene that encodes a mitochondrial protein promoting cytochrome c release. Exp Cell Res, 2005, 302: 194205.

[12] Gonzalez P, Duenau M, Charpentier S, Normand T, Mollet L, Dubois M, Legrand A. Destabilization of membranes containing cardiolipin or its precursors by peptides derived from mitogaligin, a cell death protein. Biochemistry, 2007, 46: 7374-7382.

[13] Gonzalez P, Robinet P, Charpentier S, Mollet L, Normand T, Dubois M, Legrand A. Apoptotic activity of a nuclear form of mitogaligin, a cell death protein. Biochem Biophys Res Commun, 2009, 378: 816-820.

[14] Cao XT. Immunological techniques and applications. Beijing: Science Press, 2010.

[15] Hu QL, Zhang SF, Yang XY, Yu MH, Zhu-Ge H. Bufo gargarizans mcl-1 cloning and its prokaryotic recombinant protein expression. YaoXueXueBao, 2013, 48(10): 1624-1628.

Citation: Enhao Fang. et.al, "Rabbit Galig Discovery and its Prokaryotic Recombinant Protein Expression", International Journal of Research Studies in Biosciences (IJRSB), vol. 6, no. 5, pp. 6-11, 2018. http://dx.doi.org/10.20431/2349-0365.0605002

Copyright: (c) 2018 Authors. This is an open-access article distributed under the terms of the Creative Commons Attribution License, which permits unrestricted use, distribution, and reproduction in any medium, provided the original author and source are credited. 